\title{
Review of an ERP System Supporting Lean Manufacturing
}

\author{
Kenn Steger-Jensen* and Hans-Henrik Hvolby \\ Centre of Supply Chain Integration \\ Department of Production, Aalborg University, Denmark.
}

\begin{abstract}
This paper presents a case study and discusses the issues of implementing Lean manufacturing within a global organisation and the adoption of it in an Erp-system. It discusses and presents how the modelling and design of the manufacturing planning and control task can be done, and how it is implemented within the Erp system, to support the daily operation in the case company. The Erp system used by the organisation is Oracle Ebusiness suite, but not the whole suite. Regarding adoption of Lean manufacturing, the Erp-systems' capabilities of supporting manufacturing planning and control $\mathrm{Mpc}$ in a Lean environment are in focus.
\end{abstract}

\section{Introduction}

A common misconception about Lean is that it does not mix well with information technology systems. But, as Lean spreads beyond the relatively stable manufacturing environment it originally was designed to support, companies realise that information technology can play a vital role. Information technology systems, such as Erp, can be used successfully to support Lean transformations, especially for manufacturers who have highly variable demand for a large number of low volume products, and who operate in mixed-mode manufacturing environments.

While Erp systems once had a reputation for not supporting Lean initiatives, times have changed completely. There are Erp systems that do support Lean. However, manufacturers should examine the capabilities of their Erp systems closely to examine whether they can support their Lean initiative adequately.

The paper is a contribution to Mpc issues related to capabilities of Erp systems and IT-technologies within a Lean environment, and it is structured as follows: In section 2, the demand-driven Lean requirements to Mpc are discussed. In section 3, the case company is presented. In section 4, modelling and design of the Mpc task within the Erp system is presented and the case results are discussed. Finally, conclusion and further research are outlined in section 6 .

Please use the following format when citing this chapter:

Steger-Jensen, K. and Hvolby, H.-H., 2008, in IFIP International Federation for Information Processing, Volume 257, Lean Business Systems and Beyond, Tomasz Koch, ed.; (Boston: Springer), pp. $67-74$. 


\section{Demand-driven Lean Requirement to Mpc}

The growing competition and truly relentless pressures to increase customer satisfaction have forced manufacturers to become more demand-driven. This has triggered a dramatic shift in the focus of Lean planning processes away from production and inventory and towards a much more demand-driven approach.

The typical approaches for Lean used by most companies today do not provide an optimal return on investment for companies. The missing link between Lean goals and successful projects that produce the intended result is a strategy for Lean. Many companies start off with a tactical approach, rather than a strategic one. This is a key factor in the high percentage of failed programs within Lean; less than $20 \%$ of companies are successful with Lean [1].

\begin{tabular}{|l|l|}
\hline Reduce non value-added manufacturing and supply chain costs & $66 \%$ \\
\hline Implement continuous culture and methods & $52 \%$ \\
\hline Implement manufacturing and supply chain flexibility & $38 \%$ \\
\hline Customer demand driven maunfacturing & $29 \%$ \\
\hline Focus on Customer value-adding activities & $27 \%$ \\
\hline Reduce inventory and assest required to produc and deliver poduct & $27 \%$ \\
\hline Improve product quality & $20 \%$ \\
\hline
\end{tabular}

Fig. 1. Best-in-class Strategic Actions of Lean [2]

As shown in Figure 1, a recent survey show that $66 \%$ of best-in-class companies point out cost reduction in manufacturing and the supply chain as the key target for their Lean initiative. The other actions are operational, cultural and quality focused. The lesson learned is that Lean in practice is viewed as a cost-reduction strategy, not as a market domination one, by the majority of companies. Companies should primarily focus on Lean as a growth-enabler rather than a cost reducer, and a change in perspective is required.

A proper Erp system can help overcome the challenges of applying Lean to the demand-driven manufacturers face. The combination of real-time data collection and monitoring; the ability to map highly variable customer demand to a smooth manufacturing plan along with various operational capabilities such as real-time pull requirements and backflushing transactions has actually placed Erp systems in the centre of the new Lean evolution.

The key point is that the Erp system is a tool to handle the increasing manufacturing design activities, daily operation activities and transactions, and it is an important tool to increase innovation and reduce delivery time, as a result of moving beyond the relatively stable manufacturing environment to a more demanddriven approach with highly variable, low volume demand.

This paper focuses on the Erp system's capability to support the Mpc issues for demand-driven manufacturing, which Mto belongs to in general.

The following issues are of special interest in the following case study: 
- Overcome the difficulty of calculating Heijunka schedules (Uniform Plant Loading), having an increased number of products with low volume. Demand smoothing is important as the production lines are designed based on an average daily mix.

- To implement dynamic line balancing and customer order scheduling to improve flexibility.

- Implement smaller levelling periods and more frequent adjustment of Kanban loop and sizes, as customers require shorter delivery time.

Furthermore, the order management is more complex, since the interface to the manufacturing system is demand-driven with highly variable, low volume demand, which also increases the complexity of the supplier network and inventory control.

\section{Case Company's Goals and Issues}

The company's competitive advantages and priorities were (and still are) product innovation, flexibility and delivery in the described order. To increase and support the competitive priorities and contents, responsiveness to the changing customer demand needs to be improved.

The company has good experience with Lean manufacturing on the shop floor level. The products involve a high amount of engineering skills and are among the most reliable products on the marked. There are some seasonal fluctuations in sales, primarily on the professional markets.

An analysis shows that the primary issues to the responsiveness are 1) the approach to Mpc and 2) the reduced use of the Erp system. Also the new product development process was an issue, as the Erp system was not used in this activity.

In general, the Erp system was not used to integrate and to streamline the business processes nor the information flows, as the Erp system was decoupled from the order management and down to the shop floor control. All information flow from order entry to manufacturing release was handled with spreadsheets, email and other sub systems and has to be entered manually into the Erp system. The Erp system was more or less only used for costing and accounting and to coordinate and deliver due dates and availability information for downstream purposes in the supply chain.

Order Management was not able to use the planning and control functionality within the Erp system due to lack of master data setup. Because of the demand fluctuation, a lot of manual re-planning was necessary. Due to the Mto approach the order management process was quite complex and difficult to handle without using facilities in the Erp-system such as planning and demand time fences, available-topromise, capable-to-promise, scheduling rules, etc. This made the order management process slow and time-consuming and caused increased backlogs and backorders. As a consequence the competitive priority, delivery, was very low and it was difficult to fulfill the delivery goals.

The master data was organised for manufacturing, assembly and shop floor activities in general, but maintained in another system not integrated with the Erp system. 
Therefore Mpc was primarily made within spreadsheets, since the setup and modelling of master data within the Erp system was insufficient. Finally the employee knowledge on the Erp system's capability for Mpc was insufficient as well.

The company's production system is based on the demand flow technology principles of Costanza [3]. The lead-time is between 80 minutes and approx. 50 hours per unit, with short changeover time. The production layout is line flow-based and split into two groups: four feeder lines and one main line, which is used for whole product mixes. All material supplies are controlled through Kanban. The in process Kanban on the main line contains one unit.

An analysis of the Erp system showed that it was capable of supporting a Lean manufacturing environment and should be used for this puspose.

\section{Modelling and Design of the Mpc and Control Task}

The new Mpc concept is presented in figure 2. The customer order de-coupling point is at the raw material inventory, and the manufacturing is split into two planning areas. One planning area is the material supply to the feeder lines and main line, based on Kanban, and the other one is the lines. All items are controlled through two bin Kanban systems. The pull sequence of external Kanbans (items from suppliers delivered to inventory) are controlled by 5 Kanban cards and items from inventory to row in-process and the lines are controlled by 2 Kanban bins, which means that only the size of the Kanbans needs to be calculated.

The Kanban systems design is based on a simulation of the flow within the Erp system. Internal Kanbans are used on three different types of items. A-items are physically big and of high price. 4 different sizes of Kanban bins are used for Bitems. The size of the item is the decision variable for using a specific Kanban bin size. C-items are e.g. bolts and nots which are small and cheap compared to the final product costs.

By using Kanban on all items the material requirements are planned when generating the Kanban Plan, which can be done based on a forecast schedule or Mps. This gives the opportunity to level both supplies and the production rate at the same time, and more specific to balance the capacity requirements on line operation level and material and inventory requirements for specific items. Only the production layout and the in-process-Kanban size of one is preserved, all other master data is redesigned. Items, Bom's, and routings have all revision control and audit on data, which ensures that the right master data and information is used. All master data is defined and maintained in the Erp system. The manufacturing engineering instruction is maintained in another application and linked as an attachment to the standard operations in the Erp system. The Mpc master data setup is presented in figure 3 . 


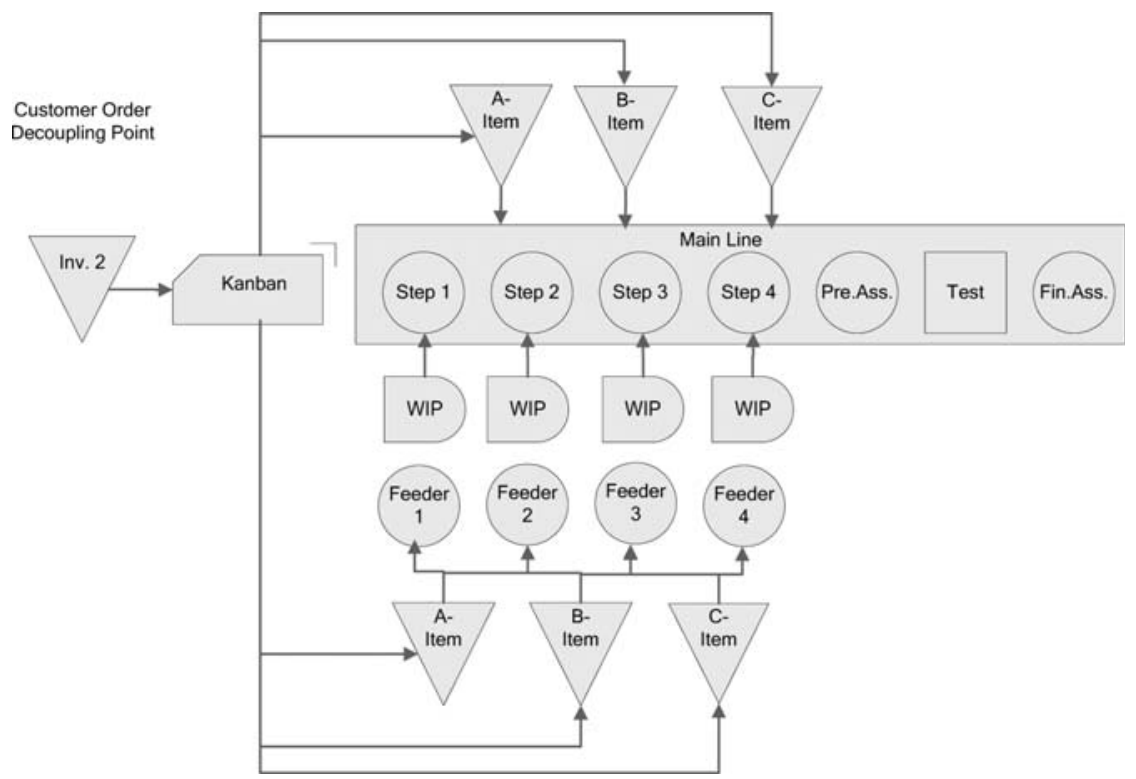

Fig. 2. The Mpc concept contains two planning areas: the lines and the supply from inventory to the lines, respectively

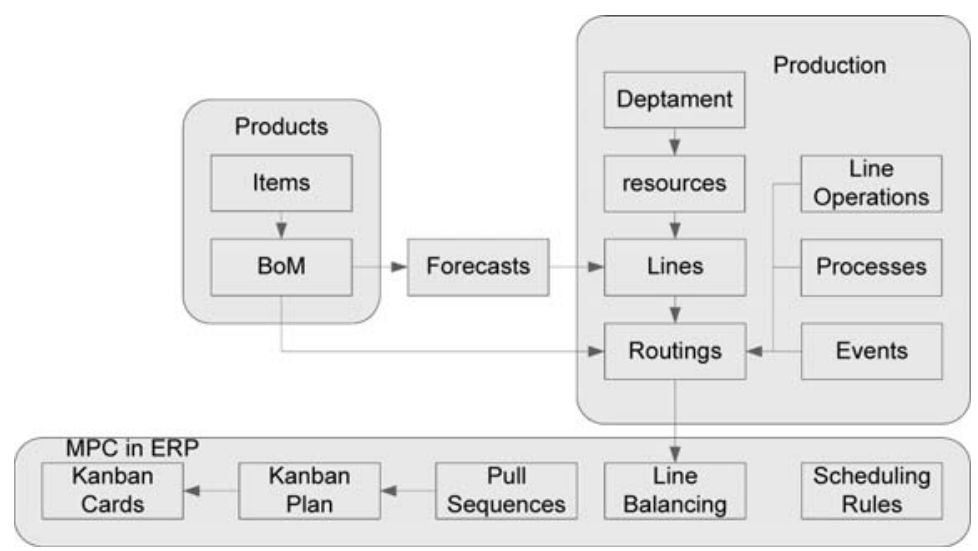

Fig. 3. The master data design setup and relationship in the Erp system

The Bom and related routing is designed to support both sales configuration and production on shop floor level at the same time. The Bom design supports order management, since it is now possible to make available-to-promise requests. It is also now possible to forecast both on products and product families and to derive the forecast on Stock Keeping Units, based on aggregated forecast and time series 
models. Most of all, the redesign of the master data gives an opportunity to do dynamic Kanban calculations.

The routing is designed as a gross routing, which contains all line operations, processes and events for each product and product family. This design gives the capability to simulate resource requirement and dynamic line balancing at the same time based on forecast (e.g. product family level) and based on specific customer demand on product level. Thereby the routings also support the order management process by capable-to-promise requests and is an important and effective integration to the planning and control process.

The gross routings need to be designed and modelling very carefully, since dynamic line balancing can become an issue. In general, the defined cycle time for each product is used as input to the line balancing. The line balancing complexity increases, as all products are produced on the same lines, and each has its own cycle time. Therefore, the product mix issue must be considered during line balancing too. The purpose of line balancing is to allocate events to processes, which are executed by a line operation. Since some events must be executed by the same process, allocating events between two processes during dynamic line balancing is not possible. Therefore constraints on events are needed to specify how to allocate and split events to processes within the route. This constraint ensures that the line balancing is calculated correctly according to the specified cycle time for each product.

Due to the Mto approach, order management needs scheduling rules to do the order planning effectively. Sequencing rules consist of a combination of one or more sequencing criteria and one scheduling algorithm. Sequencing criteria are used to determine the scheduling priority of sales orders.

The criteria used are first order request date, and then order entry date as second. This means that if two orders have the same request date the order first entered is scheduled first.

Scheduling algorithms are used to smooth demand by restricting the number of assemblies scheduled in any given day. Demand smoothing is important since the lines are designed based on an average daily product mix. There are three levels of smoothing, within the Erp system: No Level Loading, Level Loading, and Mixed Model, where the last one is used.

The mixed model map is a tool that displays the processes and products for a given line as well as the associated weighted times to complete the process. The mixed model map also displays the labor, machines and In-Process-Kanban (Ipk) resources needed to support forecast demand. This information is used to decide how to regroup events into line operations to balance the line. Mixed Model performs level loading for the whole product mix, and avoids batching. For example a mix of 100 A products and $50 \mathrm{~B}$ products could generate a pattern of AAB which would be repeated 50 times to schedule the total demand. This provides the most consistent pace through the main line, and will cause the least disruptions to the supply chain, and the fastest way to produce a whole mix.

This is a preferred method of demand smoothing, since it will minimize the gap between the design mix and the actual demands. This method is useful if customers are somewhat flexible in their delivery dates, and set-up times are insignificant. The other two methods can be summarized as follows. 
With a daily rate level, a demand ratio is calculated, based on the mix of demand over the time horizon. This ratio is multiplied by the amount of available capacity each day to determine how much of each item will be scheduled on a given day. Items are then prioritised based on the sequencing criteria.

With no level loading, the system performs no demand smoothing. Orders are scheduled solely based on the sequencing criteria and the line capacity. This method is useful when customers are not flexible regarding delivery dates. For example: a customer is running a Jit facility that needs delivery exactly at the requested date. But scheduling without level loading may create a mix of products that is very different from the mix line design. If products vary significantly in build time, set-up time, or the parts used, it will cause either large imbalances to the line, or shortages of material in Kanbans.

As an example: Assume Product A takes 2 hours to assemble at one operation, and product B only takes 1 hour. The line is designed to make 4 A's and 8 B's every day (the line runs 16 hours each day). But today, customer orders are received for 8 A's and 4 B's. This new mix requires 20 hours to assemble at the operation, and then there is not enough capacity to produce the requested mix without using overtime.

The Mpc environment reduces maintenance of the master data in general. Figure 4 presents the Mpc production setup in the Erp system. The new Mpc approach has, combined with the improved use of the Erp-system, increased the speed of innovation, flexibility, manufacturing plan and control quality as well as delivery performance. The company has obtained some of the fundamental means to support fulfilment of the ultimate goal. The purpose of the case study has been to demonstrate the value of using Erp systems within a Lean manufacturing environment.

Single source of data by using the Erp system for handling the information flow and the master data has reduced the manual load and increased responsiveness.

The case company has more than the one manufacturing location where the same Erp system is used. As the Erp system is able to handle more than one organisation it is now possible to deliver and transfers a full package of master data setup and Mpc to another manufacturing site without redesign.

\section{Conclusion and Further Research}

The paper demonstrates the value of using Erp-systems within a Lean manufacturing environment. Based on the case study, the company has increased both its innovation skills of speed and flexibility, as well as its manufacturing plan quality and delivery performance.

Further development of methods and techniques for dynamic line balancing is needed, since the balance between material flow and resource activities is too restricted compared to what is needed. The main issue is that balanced and stabile material flow on e.g. the main manufacturing line does not by default give a balanced and stabile material flow upstream and visa versa.

This is in practice an issue for low volume and highly variable demand. 


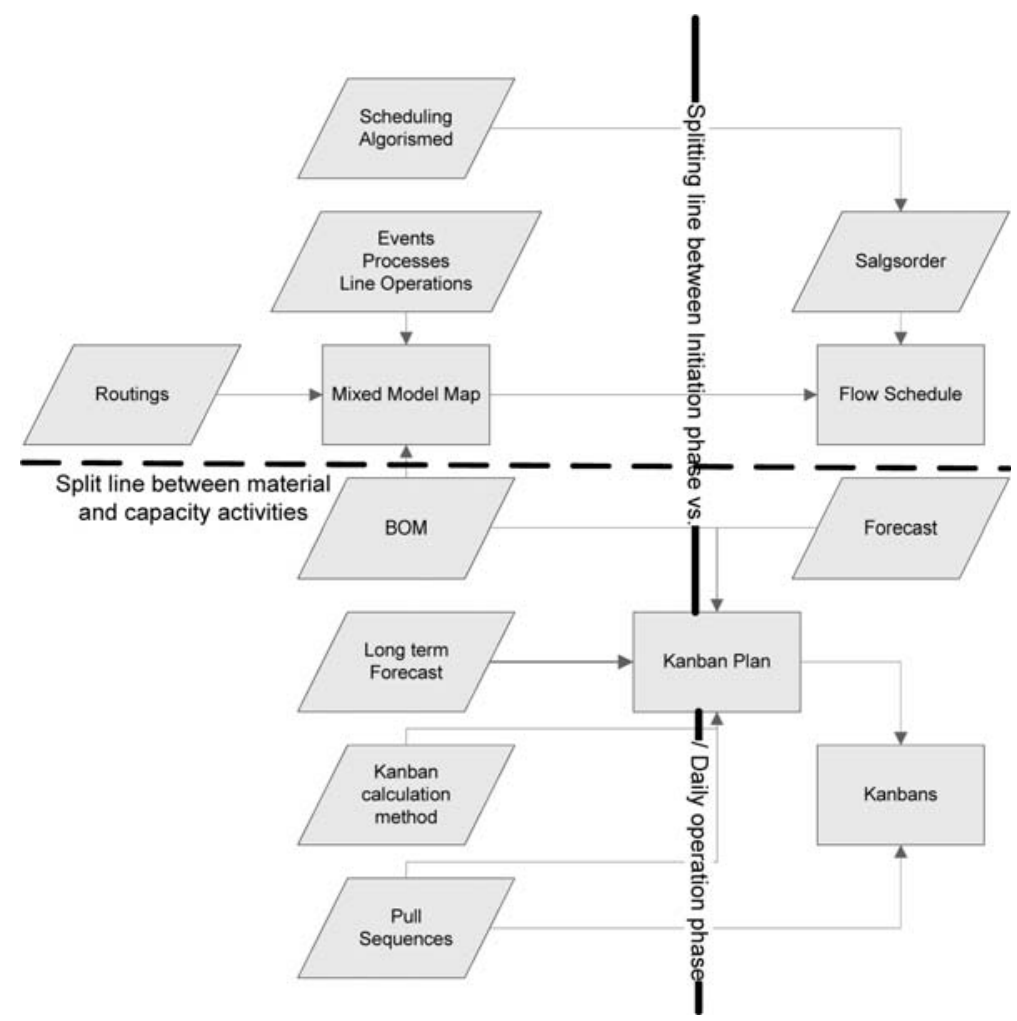

Fig. 4. Mpc production setup in the Erp system. It contains two splitting lines, one between material and capacity activities and one between initiation vs. daily operation phase activities

\section{References}

1. Kilpatrick, Jerry D and Osborne, Robert; The R(E)volution of Lean, Business Breakthroughs Inc, 2006.

2. Biddle, Jane, "The Lean Benchmark Report: Closing the Reality Gap", March 2006. AberdeenGroup. 20 March 2006, www.aberdeen.com.

3. Costanza, J. R; The quantum leap in speed to market, third ed., John Costanza Institute of Technology, Inc., Isbn: 0-9628182-1-6, 1996. 